\title{
GIFFORD PINCHOT
}




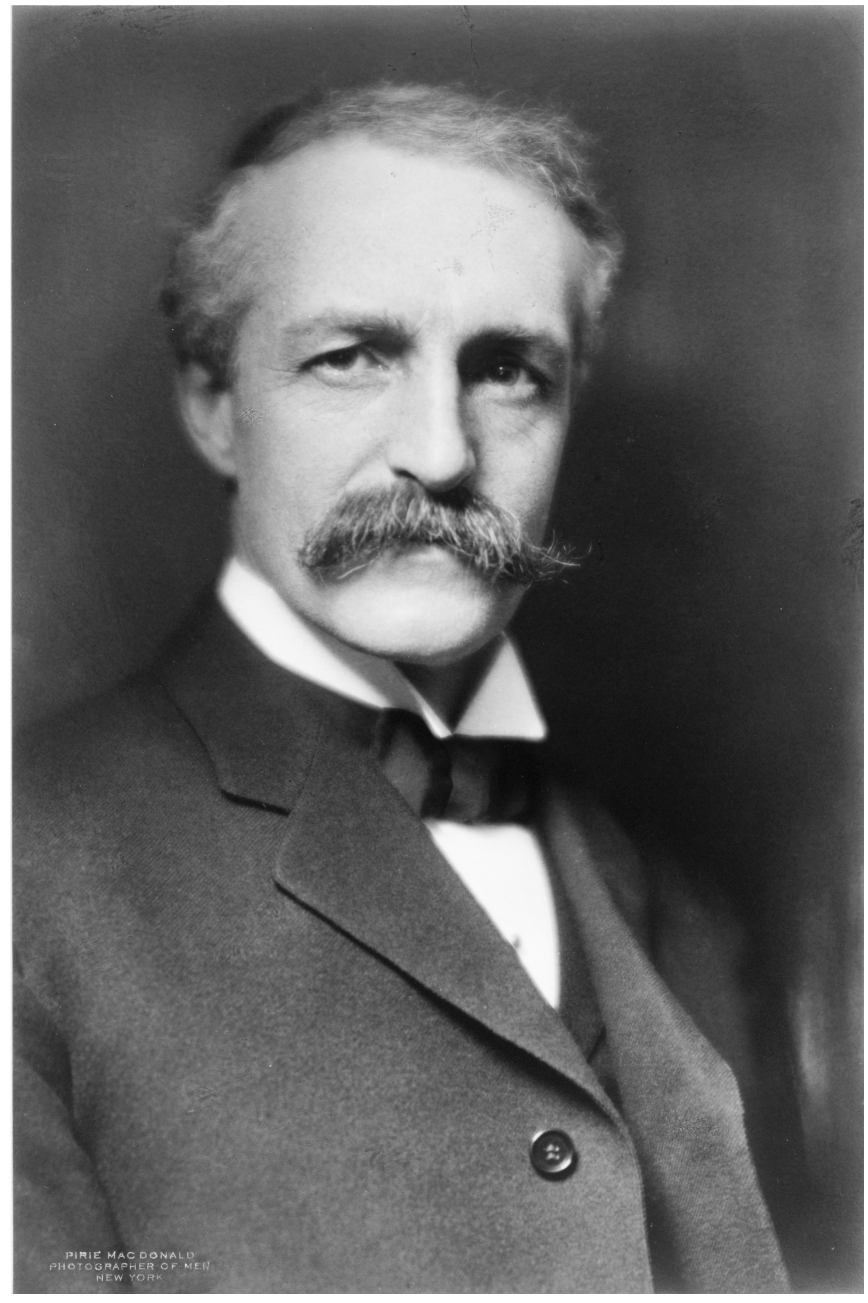




\title{
GIFFORD PINCHOT
}

\section{SELECTED WRITINGS}

\author{
EDITED BY \\ CHAR MILLER
}

The Pennsylvania State University Press

University Park, Pennsylvania 
Library of Congress Cataloging-in-Publication Data

Names: Pinchot, Gifford, 1865-1946, author. | Miller, Char, 1951- , editor.

Title: Gifford Pinchot : selected writings / edited by Char Miller.

Description: University Park, Pennsylvania : The Pennsylvania State University

Press, [2017] | Includes bibliographical references and index.

Summary: "Collection of essays by Gifford Pinchot (1865-1946), founding chief of the U.S. Forest Service and twice governor of Pennsylvania. The social, political, and scientific insights in these essays anticipate many contemporary

environmental-policy dilemmas and the growing demand for environmental justice"-Provided by publisher.

Identifiers: LCCN 2016058255| ISBN 9780271078410 (cloth : alk. paper) |

ISBN 9780271078427 (pbk. : alk. paper)

Subjects: LCSH: Forests and forestry. | Pennsylvania-Politics and government-1865-1950. | LCGFT: Essays.

Classification: LCC SD123 .P56 2017 | DDC 634.909748-dc23

LC record available at https://lccn.loc.gov/2016o58255

Copyright (C) 2017 The Pennsylvania State University

All rights reserved

Printed in the United States of America

Published by The Pennsylvania State University Press, University Park, PA 16802-1003

The Pennsylvania State University Press is a member of the Association of American University Presses.

It is the policy of The Pennsylvania State University Press to use acid-free paper. Publications on uncoated stock satisfy the minimum requirements of American National Standard for Information Sciences-Permanence of Paper for Printed Library Material, ANsI z39-48-1992.

This book is printed on paper that contains $30 \%$ post-consumer waste. 
For Al Sample 
